Erratum Zu:

\title{
Günter Fandel
}

\section{Erratum zu: Z Betriebswirtsch \\ DOI 10.1007/s11573-009-0315-0}

In der Beschreibung des Beitrages Diepold und Dzienziol ist im zweiten Satz leider ein Fehler vorhanden.

„...nur noch unvollständig verkauft werden können ..., , sollte lauten „... nur noch vollständig verkauft werden können ....".

Online publiziert: 07.11.2009

(C) Gabler-Verlag 2009

Die Onlineversion des Originalbeitrages ist erreichbar unter doi: 10.1007/s11573-009-0315-0

G. Fandel $(\bowtie)$

Editor-in-Chief

FernUniversität in Hagen, Hagen, Deutschland

E-Mail: ZFB@FernUni-Hagen.de 